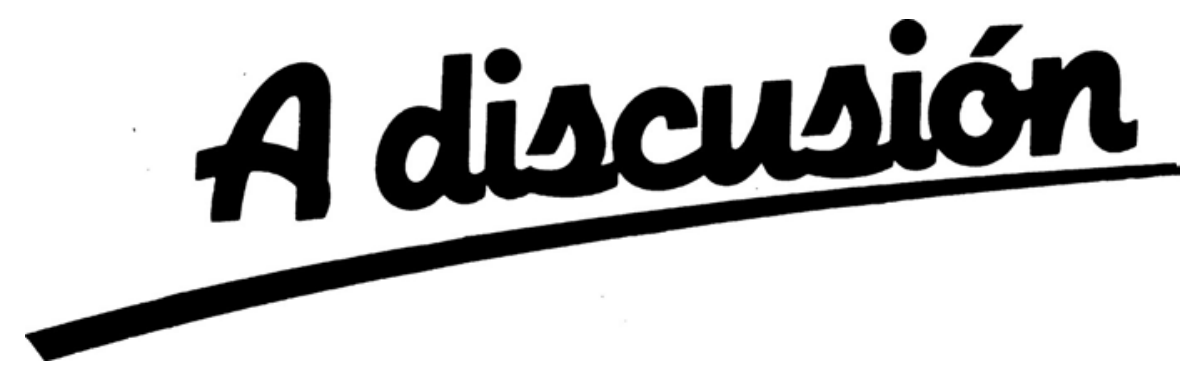

\title{
PREFERENCE SHOCKS FROM AGGREGATION: TIME SERIES DATA EVIDENCE*
}

\author{
Lilia Maliar and Serguei Maliar**
}

WP-AD 2003-35

Correspondence: Departamento de Fundamentos del Análisis Económico, Universidad de Alicante, Campus San Vicente del Raspeig, Ap. Correos 99, 03080 Alicante, Spain. E-mails: maliarl@merlin.fae.ua.es and maliars@merlin.fae.ua.es.

Editor: Instituto Valenciano de Investigaciones Económicas, S.A.

Primera Edición Noviembre 2003

Depósito Legal: V-5023-2003

IVIE working papers offer in advance the results of economic research under way in order to encourage a discussion process before sending them to scientific journals for their final publication.

\footnotetext{
* We thank Jordi Caballe, Finn Kydland, Franck Portier, Michael Reiter, Andrew Scott and especially two anonymous referees and co-editor, John Galbraith, for useful comments. We are grateful to Morten Ravn for his guidance. Any remaining errors are the sole responsibility of the authors. An earlier version of this paper was published as an the Ivie WP-AD 2001-07. This research was supported by the Instituto Valenciano de Investigaciones Económicas and the Ministerio de Ciencia y Tecnología de España, the Ramón y Cajal program and BEC 2001-0535.
}

** Dpto. Fundamentos de Análisis Económico, Universidad de Alicante. 


\title{
PREFERENCE SHOCKS FROM AGGREGATION: \\ TIME SERIES DATA EVIDENCE
}

\section{Lilia Maliar and Serguei Maliar}

\begin{abstract}
We investigate the impact of preference shocks on the aggregate dynamics of the U.S. economy in the context of a neoclassical growth model derived from aggregation. The aggregation result we use is as follows: if markets are complete and if agents have identical preferences of the addilog type, then the heterogeneous-agent economy where agents are subject to idiosyncratic productivity shocks behaves as if there was a representative consumer who faces shocks to preferences and technology. We estimate the parameters in the aggregation-based model from the aggregate time-series data and compute the numerical solution. We find that the preference shocks play an important role in the aggregate labor-market fluctuations.
\end{abstract}

JEL Classification: C73, D90, E21

Key words: neoclassical growth model, heterogeneous agents, aggregation, business cycles, preference shock 


\section{Introduction}

Real Business Cycle (RBC) models, in which fluctuations are caused exclusively by technology shocks, proved to be remarkably successful in accounting for the properties of business cycles, observed in actual economies. There are some exceptions, however. ${ }^{1}$ One important shortcoming of the typical RBC model is that it predicts a strong positive correlation between working hours and productivity (wages). The correlation between these two variables in the data is however weakly negative. The latter empirical regularity is originally documented by Dunlop (1938) and Tarshis (1939) and is often referred to in the literature as the "Dunlop-Tarshis" observation. ${ }^{2}$

Bencivenga (1992) demonstrates that extending RBC models to include preference shocks can help to account for the Dunlop-Tarshis observation. ${ }^{3}$ To be specific, she incorporates preference shocks in a variant of the standard neoclassical growth model by Kydland and Prescott (1982) with a logarithmic utility function, a Cobb-Douglas production function and full depreciation of capital. She calibrates the preference shocks to match aggregate time-series data on the U.S. economy and finds that the model generates a weak negative correlation between working hours and productivity. Nonetheless, the model considered in Bencivenga (1992) has difficulties in replicating some other features of the data. In particular, it over-states dramatically the volatility of consumption (by a factor of six) as well as the volatilities of such a model's variables as output, labor and labor productivity (by a factor of two-four); it counterfactually predicts that consumption is more volatile than output and that labor productivity is negatively correlated with output; etc.

Maliar and Maliar (2003a) consider a neoclassical economy with heterogeneous agents and show that, at the aggregate level, preference shocks can arise as a consequence of idiosyncratic labor productivity shocks. To be precise, the following aggregation result is shown: if markets are complete and if agents have identical preferences of either the Cobb-Douglas or addilog types, then a heterogeneous-agent economy, where idiosyncratic labor productivity shocks are the only source of uncertainty, behaves as if there was a

\footnotetext{
${ }^{1}$ See King and Rebelo (1999) for a discussion.

${ }^{2}$ A large body of the literature focuses on this "labor market puzzle", e.g., Christiano and Eichenbaum (1992), Bencivenga (1992), Gomme and Greenwood (1995), Maliar and Maliar (2001, 2003a).

${ }^{3}$ Bencivenga (1992) argues that preference shocks may be interpreted as resulting from shocks to household production or from changes in relative prices.
} 
representative consumer who faces three kinds of shocks, to preferences, to technology and to labor input. ${ }^{4}$ Particular assumptions about idiosyncratic shocks do not affect the structure of the constructed one-consumer model but just the stochastic properties of the aggregate shocks. Maliar and Maliar (2003a) calibrate the model to reproduce the distribution of wealth and the process for the individual labor earnings from the U.S. household data. This paper finds that preference shocks from aggregation have virtually no effect on aggregate dynamics. ${ }^{5}$

There are several differences between the models studied in Bencivenga (1992) and Maliar and Maliar (2003a), which can potentially explain why preferences shocks are quantitatively important in the former model but play little role in the latter model. Specifically, Bencivenga (1992) considers two types of preference shocks (one to the consumption term and another to the leisure term of the additively separable utility function); she assumes full depreciation of capital; and she calibrates the properties of the preference shocks from aggregate time-series data. In contrast, the model by Maliar and Maliar (2003a) contains just one type of preference shock (one to the leisure term of the additively separable (addilog) utility function); it has partial depreciation of capital; and it is calibrated to reproduce evidence from household data.

The purpose of the present paper is twofold. First, given the difference seen between the results of Bencivenga (1992) and those of Maliar and Maliar (2003a), we attempt to determine under precisely what conditions preference shocks are important in aggregate dynamics. Second, given that the model considered in Bencivenga (1992) has several undesirable features, we investigate whether the aggregation-based variant of the neoclassical growth model derived in Maliar and Maliar (2003a) can generate empirically plausible predictions if it is calibrated to reproduce aggregate time-series data, as in Bencivenga (1992).

To estimate the parameters of the aggregation-based model, we use the aggregate time-series data on the U.S. economy. We assume that the preference and technology shocks follow a first-order autoregressive process and we

\footnotetext{
${ }^{4}$ Shocks from aggregation do not arise in economies derived from aggregation under the assumption of time-invariant individual characteristics, e.g., Chatterjee (1994), Atkeson and Ogaki (1996), Caselli and Ventura (2000), Maliar and Maliar (2001).

${ }^{5}$ Maliar and Maliar (2003a) show that another type of shock from aggregation, namely, the one to labor input, can have a non-trivial effect on the aggregate dynamics. This type of shock is not considered in the present paper.
} 
estimate all the model's parameters, including a matrix of the transitional probabilities and the variances of the error terms, by Hansen's (1982) Generalized Method of Moments (GMM) procedure. ${ }^{6}$ We then calibrate the model and simulate the solution.

We find that under the above calibration procedure, preference shocks have a non-trivial effect on the model's predictions. As Bencivenga (1992) does, we too obtain a weak correlation between productivity and working hours. This prediction is robust to changes in the values of the key model's parameters, including the discount factor, the intertemporal elasticities of consumption and leisure and the autocorrelation coefficients. As far as the other predictions are concerned, they are practically identical to those generated by the benchmark Kydland and Prescott's (1982) model and are in line with the U.S. data. That is, our model does not suffer from the problems encountered in Bencivenga (1992).

Our analysis has the following two implications: First, whether preference shocks affect aggregate dynamics or not depends crucially on how the model is calibrated. We argue that the aggregate preference shocks play a very little role in the analysis of Maliar and Maliar (2003a), because, under the assumptions used in this paper, idiosyncratic shocks are almost uncorrelated across agents, so that they, literally, offset each other when they are aggregated in the preference shocks. In actual economies, however, idiosyncratic shocks can be significantly correlated, which is likely to be reflected in the aggregate time series data. ${ }^{7}$ The result is that the preference shocks measured in the present paper from the aggregate time series data are much greater than those computed in Maliar and Maliar (2003a). Secondly, given that our aggregation-based model with technology and preference shocks can account remarkably well for the U.S. data, we can attribute all the shortcomings of Bencivenga's (1992) model to the two assumptions that distinguish her setup from ours, namely, full depreciation of capital and shocks to the consumption term of the utility function (which are absent in our model). Indeed, full de-

\footnotetext{
${ }^{6}$ The model in Bencivenga (1992) admits a closed-form solution, which simplifies the estimation procedure since the maximum likelihood function can be constructed explicitly. We cannot adopt this approach, as our more general setup does not admit a closed-form solution. Instead, we use the GMM procedure, which makes it possible to estimate the parameters without knowing a solution.

${ }^{7}$ The simplest example that shows the existence of such a correlation is an empirical regularity that workers tend to loose their jobs during recessions and find jobs during expansions.
} 
preciation makes capital stock excessively volatile, which magnifies the size of fluctuations in general, while the shocks to the consumption term of the utility function exaggerate consumption fluctuations even further, leading to the counterfactual prediction that consumption is more volatile than output.

This paper is organized as follows: Section 2 describes the model derived from aggregation and outlines the estimation and solution procedures. Section 3 presents the numerical results, and finally, Section 4 concludes.

\section{The model and the methodology of the nu- merical study}

The economy is populated by an infinitely-lived representative consumer who has a momentary utility function of the addilog type and who solves the following intertemporal utility maximization problem:

$$
\max _{\left\{c_{t}, k_{t+1}, h_{t}\right\}_{t \in T}} E_{0} \sum_{t=0}^{\infty} \delta^{t}\left\{\frac{c_{t}^{1-\gamma}-1}{1-\gamma}+A X_{t} g^{t(1-\gamma)} \frac{\left(1-h_{t}\right)^{1-\sigma}-1}{1-\sigma}\right\},
$$

subject to

$$
c_{t}+k_{t+1}=(1-d) k_{t}+\theta_{t} f\left(k_{t}, g^{t} h_{t}\right)
$$

where the initial condition $\left(k_{0}, \theta_{0}, X_{0}\right)$ is given. Here, $E_{0}$ is the operator of the conditional expectation; $c_{t}, k_{t}$ and $h_{t}$ denote consumption, capital and hours worked, respectively; $\delta \in(0,1)$ is the discount factor, $\gamma, \sigma, A>0$ are the parameters of the utility function; $d \in(0,1]$ is the depreciation rate of capital; $f\left(k_{t}, g^{t} h_{t}\right)=k_{t}^{\alpha}\left(g^{t} h_{t}\right)^{1-\alpha}$ with $\alpha \in(0,1)$ is the Cobb-Douglas production function, and $g$ is the rate of the labor-augmenting technology progress. The variables $\theta_{t}$ and $X_{t}$ will be referred to as technology and preferences shocks, respectively.

Maliar and Maliar (2003a) show that the representative-consumer model (1), (2) can be viewed as the outcome of aggregation. It is specifically shown that if markets are complete and if all agents have identical preferences of the addilog type, then a neoclassical economy, where agents face idiosyncratic shocks to earnings, behaves as if there was a representative consumer who solves the utility maximization problem (1), (2). 
We calibrate the model in a way that is standard in the RBC literature, which is by assuming that shocks follow an autoregressive process:

$$
\left[\begin{array}{c}
\ln \left(\theta_{t}\right) \\
\ln \left(X_{t}\right)
\end{array}\right]=\left[\begin{array}{cc}
\rho_{\theta \theta} & \rho_{\theta X} \\
\rho_{X \theta} & \rho_{X X}
\end{array}\right]\left[\begin{array}{c}
\ln \left(\theta_{t-1}\right) \\
\ln \left(X_{t-1}\right)
\end{array}\right]+\left[\begin{array}{c}
\varepsilon_{t}^{\theta} \\
\varepsilon_{t}^{X}
\end{array}\right],
$$

where $\left\{\rho_{\theta \theta}, \rho_{\theta X}, \rho_{X \theta} \rho_{X X}\right\}$ are the autocorrelation coefficients, $\varepsilon_{t}^{\theta} \sim N\left(0, \nu_{\theta}^{2}\right)$ and $\varepsilon_{t}^{X} \sim N\left(0, \nu_{X}^{2}\right)$. We then estimate the model's parameters, including those in (3), and simulate the solutions.

To estimate the parameters, we use quarterly data on the U.S. economy ranging from $1959: 3$ to $1998: 3$. For a description of the data set see Maliar and Maliar (2003a). Unfortunately, quarterly data on aggregate efficiency hours worked, $h_{t}$, are not available, just those on aggregate physical hours worked, $n_{t}$. As shown in Maliar and Maliar (2003a), these two model's variables are related as

$$
n_{t}=1-\left(1-h_{t}\right) \cdot \pi_{t}
$$

where $\pi_{t}$ is the labor-input shock, whose stochastic properties depend on specific assumptions about the distributions of wealth and idiosyncratic shocks. We abstract from the effect associated with the labor-input shock and investigate the robustness of our results with respect to changes in the measure of labor input. We specifically consider two alternative proxies for $h_{t}$. One is the level of employment and the other is aggregate physical hours worked. Our results proved to be robust to changes in the measure of labor input used.

To estimate the model's parameters, we use Hansen's (1982) version of Generalized Method of Moments (GMM). Our estimation procedure is close to the one used in Christiano and Eichenbaum (1992). The utility parameters, $\gamma$ and $\sigma$, and the subjective discount factor, $\delta$, are not estimated. In the baseline case, we assume $\gamma=\sigma=1$ and $\delta=(1.03)^{-0.25}$. Afterwards, we analyze the robustness of our results by considering several alternative specifications for these parameters. ${ }^{8}$ We subdivide the parameters into two groups, $\Psi_{1}$ and $\Psi_{2}$, defined as

$$
\Psi_{1}=\{\alpha, A, g, d\}, \quad \Psi_{2}=\left\{\rho_{\theta \theta}, \rho_{\theta X}, \rho_{X \theta}, \rho_{X X}, \nu_{t}^{\theta}, \nu_{t}^{X}\right\} .
$$

\footnotetext{
${ }^{8}$ Strictly speaking, when $\sigma=1$, we have $X_{t}=X$ for all $t$, i.e., the preference shock disappears from the representative-agent model (1), (2) (see Maliar and Maliar, 2003a). However, an $\varepsilon$-deviation of $\sigma$ from one is sufficient to revive the preference shocks. Also, as we shall see, all of the tendencies we observe for the case $\sigma=1$ are robust to changes in $\sigma$. We stick to the case of $\sigma=1$ merely for the sake of convenience.
} 
We then proceed in two steps: First, we estimate the parameters from the group $\Psi_{1}$ by employing the first-moment conditions of the model (1), (2) and compute the residuals $\theta_{t}$ and $X_{t}$. Secondly, we estimate the parameters from the group $\Psi_{2}$ by using the residuals. Given that the stochastic properties of the processes for $\theta_{t}$ and $X_{t}$ are not known, we compute the instrumental variable estimator at both steps. As instruments, we use the variables consumption, capital, output and hours worked, taken up to eight lags. The first-moment conditions, employed for estimating the parameters from $\Psi_{1}$, are given in the Appendix. The parameters from $\Psi_{2}$ are estimated according to $(3)$.

The estimates of the parameters from $\Psi_{1}$ obtained in the baseline model are as follows:

$$
\alpha=\underset{(0.0016)}{0.3341,} \quad A=\underset{(0.008)}{3.317}, \quad g=\underset{(0.0001)}{1.0047}, \quad d=\underset{(0.0001)}{0.0209},
$$

where the numbers in brackets are the standard deviations. These estimates are practically identical to those reported by Christiano and Eichenbaum (1992). Our estimates proved to be robust to modifications in the set of instruments and in the number of lags. To economize on space, we do not report the parameters from $\Psi_{1}$, just those from $\Psi_{2}$, for the remaining values of $(\gamma, \sigma, \delta)$.

We parameterize the model by using the values of the parameters, which have been previously estimated by GMM, and solve for equilibrium. To compute numerical solutions, we employ the parameterized expectations algorithm by den Haan and Marcet (1990). We restrict the time series solution by imposing "moving bounds", as described in Maliar and Maliar (2003b), which resolves the problem of finding a good initial condition and makes it possible to systematically achieve convergence starting from the non-stochastic steady state. We approximate the conditional expectations by a second-order degree exponentiated polynomial. The length of simulations was 10000, and the iterations were performed until 5-digit precision in the polynomial coefficients was enforced.

In Table 1 and Table 2, we report the first and second moments of time series generated by the model. In the last column of Table 1, we also provide the selected first and second moments of time series in the U.S. economy. ${ }^{9}$ The reported statistics are the sample averages of the variables provided in

\footnotetext{
${ }^{9}$ Some of the moments obtained for the U.S. economy are on the upper side of those found in related studies, e.g., King, Plosser and Rebelo (1988), Smith (1993). This is
} 
Table 1. Shocks parameters and selected statistics for the U.S. and artificial economies: the baseline parameterization, $\gamma=1, \sigma=1, \delta=1.03^{-0.25}$.

\begin{tabular}{|c|c|c|c|c|c|}
\hline & \multicolumn{4}{|c|}{ Models } & \multirow{2}{*}{$\begin{array}{c}\text { U.S. } \\
\text { economy }\end{array}$} \\
\hline & Model 1 & Model 2 & Model 3 & Model 4 & \\
\hline \multicolumn{6}{|c|}{ Shocks parameters } \\
\hline$\rho_{\theta \theta}$ & $\begin{array}{c}0.99456 \\
(0.00939)\end{array}$ & - & $\begin{array}{c}0.99602 \\
(0.01588)\end{array}$ & 0.95000 & - \\
\hline$\rho_{\theta X}$ & - & - & $\begin{array}{c}0.00594 \\
(0.01551)\end{array}$ & - & - \\
\hline$\rho_{X \theta}$ & - & - & $\begin{array}{c}0.10496 \\
(0.01654)\end{array}$ & - & - \\
\hline$\rho_{X X}$ & - & $\begin{array}{c}0.99886 \\
(0.00997)\end{array}$ & $\begin{array}{c}0.92671 \\
(0.01538)\end{array}$ & 0.95000 & - \\
\hline$v_{\theta}^{2}{ }_{\theta}$ & $\begin{array}{c}0.00652 \\
(0.00055)\end{array}$ & - & $\begin{array}{c}0.00598 \\
(0.00058)\end{array}$ & $\begin{array}{c}0.00669 \\
(0.00055)\end{array}$ & - \\
\hline$v_{X}^{2}$ & - & $\begin{array}{c}0.00622 \\
(0.00051)\end{array}$ & $\begin{array}{c}0.00585 \\
(0.00046)\end{array}$ & $\begin{array}{c}0.00697 \\
(0.00045)\end{array}$ & - \\
\hline \multicolumn{6}{|l|}{ First moments } \\
\hline$c_{t} / y_{t}$ & $\begin{array}{c}0.750 \\
(0.018)\end{array}$ & $\begin{array}{c}0.748 \\
(0.012)\end{array}$ & $\begin{array}{c}0.750 \\
(0.019)\end{array}$ & $\begin{array}{c}0.751 \\
(0.023)\end{array}$ & 0.745 \\
\hline$k_{t} / y_{t}$ & $\begin{array}{l}10.365 \\
(0.539)\end{array}$ & $\begin{array}{l}10.311 \\
(0.408)\end{array}$ & $\begin{array}{l}10.359 \\
(0.589)\end{array}$ & $\begin{array}{l}10.351 \\
(0.564)\end{array}$ & 10.237 \\
\hline$n_{t}$ & $\begin{array}{c}0.211 \\
(0.004)\end{array}$ & $\begin{array}{c}0.222 \\
(0.006)\end{array}$ & $\begin{array}{c}0.212 \\
(0.008)\end{array}$ & $\begin{array}{c}0.211 \\
(0.007)\end{array}$ & 0.213 \\
\hline \multicolumn{6}{|c|}{ Second moments } \\
\hline$\sigma_{c}$ & $\begin{array}{c}0.558 \\
(0.067)\end{array}$ & $\begin{array}{c}0.290 \\
(0.033)\end{array}$ & $\begin{array}{c}0.691 \\
(0.081)\end{array}$ & $\begin{array}{c}0.480 \\
(0.063)\end{array}$ & 0.836 \\
\hline$\sigma_{y / n}$ & $\begin{array}{c}0.679 \\
(0.078)\end{array}$ & $\begin{array}{c}0.274 \\
(0.030)\end{array}$ & $\begin{array}{c}0.764 \\
(0.083)\end{array}$ & $\begin{array}{c}0.721 \\
(0.081)\end{array}$ & 1.011 \\
\hline$\sigma_{n}$ & $\begin{array}{c}0.492 \\
(0.057)\end{array}$ & $\begin{array}{c}0.806 \\
(0.090)\end{array}$ & $\begin{array}{c}1.069 \\
(0.122)\end{array}$ & $\begin{array}{l}1.408 \\
(0.153)\end{array}$ & 1.279 \\
\hline$\sigma_{i}$ & $\begin{array}{c}3.025 \\
(0.355)\end{array}$ & $\begin{array}{c}1.304 \\
(0.156)\end{array}$ & $\begin{array}{c}2.789 \\
(0.324)\end{array}$ & $\begin{array}{l}5.220 \\
(0.567)\end{array}$ & 4.793 \\
\hline$\sigma_{y}$ & $\begin{array}{c}1.153 \\
(0.127)\end{array}$ & $\begin{array}{c}0.539 \\
(0.061)\end{array}$ & $\begin{array}{l}1.120 \\
(0.130)\end{array}$ & $\begin{array}{c}1.597 \\
(0.174)\end{array}$ & 1.755 \\
\hline $\operatorname{corr}(c, y)$ & $\begin{array}{c}0.974 \\
(0.006)\end{array}$ & $\begin{array}{c}0.982 \\
(0.004)\end{array}$ & $\begin{array}{c}0.896 \\
(0.031)\end{array}$ & $\begin{array}{c}0.889 \\
(0.018)\end{array}$ & 0.923 \\
\hline $\operatorname{corr}(y / n, y)$ & $\begin{array}{c}0.989 \\
(0.003)\end{array}$ & $\begin{array}{l}-0.963 \\
(0.010)\end{array}$ & $\begin{array}{c}0.402 \\
(0.129)\end{array}$ & $\begin{array}{c}0.471 \\
(0.109)\end{array}$ & 0.715 \\
\hline $\operatorname{corr}(n, y)$ & $\begin{array}{c}0.979 \\
(0.005)\end{array}$ & $\begin{array}{c}0.996 \\
(0.001)\end{array}$ & $\begin{array}{c}0.753 \\
(0.068)\end{array}$ & $\begin{array}{c}0.890 \\
(0.032)\end{array}$ & 0.830 \\
\hline $\operatorname{corr}(i, y)$ & $\begin{array}{c}0.989 \\
(0.003)\end{array}$ & $\begin{array}{c}0.990 \\
(0.002)\end{array}$ & $\begin{array}{c}0.938 \\
(0.019)\end{array}$ & $\begin{array}{c}0.986 \\
(0.004)\end{array}$ & 0.979 \\
\hline $\operatorname{corr}(y / n, n)$ & $\begin{array}{c}0.939 \\
(0.046)\end{array}$ & $\begin{array}{l}-0.983 \\
(0.004)\end{array}$ & $\begin{array}{l}-0.287 \\
(0.138)\end{array}$ & $\begin{array}{c}0.026 \\
(0.145)\end{array}$ & 0.220 \\
\hline
\end{tabular}


Table 2. Shocks parameters and selected statistics for the artificial economies: sensitivity analysis with respect to $(\gamma, \sigma, \delta)$.

\begin{tabular}{|c|c|c|c|c|c|c|}
\hline & \multicolumn{6}{|c|}{ Models } \\
\hline & Model 5 & Model 6 & Model 7 & Model 8 & Model 9 & Model 10 \\
\hline & $\begin{array}{c}\gamma=0.75 \\
\sigma=1 \\
\delta=1.03^{-0.25}\end{array}$ & $\begin{array}{c}\gamma=1.5 \\
\sigma=1 \\
\delta=1.03^{-0.25}\end{array}$ & $\begin{array}{c}\gamma=1 \\
\sigma=0.5 \\
\delta=1.03^{-0.25}\end{array}$ & $\begin{array}{c}\gamma=1 \\
\sigma=2 \\
\delta=1.03^{-0.25}\end{array}$ & $\begin{array}{c}\gamma=1 \\
\sigma=1 \\
\delta=1.05^{-0.25}\end{array}$ & $\begin{array}{c}\gamma=1 \\
\sigma=1 \\
\delta=1.015^{-0.25}\end{array}$ \\
\hline \multicolumn{7}{|c|}{ Shocks parameters } \\
\hline$\rho_{\theta \theta}$ & $\begin{array}{c}0.99447 \\
(0.01242)\end{array}$ & $\begin{array}{c}1.00052 \\
(0.02037)\end{array}$ & $\begin{array}{c}0.99213 \\
(0.01561)\end{array}$ & $\begin{array}{c}1.00247 \\
(0.01645)\end{array}$ & $\begin{array}{c}0.99923 \\
(0.01587)\end{array}$ & $\begin{array}{c}0.99210 \\
(0.01614)\end{array}$ \\
\hline$\rho_{\theta X}$ & $\begin{array}{c}0.00979 \\
(0.01903)\end{array}$ & $\begin{array}{c}0.00453 \\
(0.01126)\end{array}$ & $\begin{array}{c}0.00196 \\
(0.01635)\end{array}$ & $\begin{array}{c}0.01127 \\
(0.01380)\end{array}$ & $\begin{array}{c}0.00879 \\
(0.01572)\end{array}$ & $\begin{array}{c}0.00310 \\
(0.01512)\end{array}$ \\
\hline$\rho_{X \theta}$ & $\begin{array}{c}0.07405 \\
(0.01273)\end{array}$ & $\begin{array}{c}0.15957 \\
(0.02232)\end{array}$ & $\begin{array}{c}0.08744 \\
(0.01476)\end{array}$ & $\begin{array}{c}0.13987 \\
(0.02074)\end{array}$ & $\begin{array}{c}0.10291 \\
(0.01651)\end{array}$ & $\begin{array}{c}0.10639 \\
(0.01685)\end{array}$ \\
\hline$\rho_{X X}$ & $\begin{array}{c}0.92131 \\
(0.01904)\end{array}$ & $\begin{array}{c}0.93270 \\
(0.01148)\end{array}$ & $\begin{array}{c}0.93813 \\
(0.01483)\end{array}$ & $\begin{array}{c}0.90954 \\
(0.01627)\end{array}$ & $\begin{array}{c}0.92658 \\
(0.01555)\end{array}$ & $\begin{array}{c}0.92978 \\
(0.01498)\end{array}$ \\
\hline$v_{\theta}^{2}$ & $\begin{array}{c}0.00602 \\
(0.00057)\end{array}$ & $\begin{array}{c}0.00597 \\
(0.00059)\end{array}$ & $\begin{array}{c}0.00595 \\
(0.00058)\end{array}$ & $\begin{array}{c}0.00604 \\
(0.00057)\end{array}$ & $\begin{array}{c}0.00599 \\
(0.00059)\end{array}$ & $\begin{array}{c}0.00599 \\
(0.00057)\end{array}$ \\
\hline$v_{X}^{2}$ & $\begin{array}{c}0.00599 \\
(0.00045)\end{array}$ & $\begin{array}{c}0.00600 \\
(0.00048)\end{array}$ & $\begin{array}{c}0.00535 \\
(0.00042)\end{array}$ & $\begin{array}{c}0.00700 \\
(0.00055)\end{array}$ & $\begin{array}{c}0.00583 \\
(0.00046)\end{array}$ & $\begin{array}{c}0.00582 \\
(0.00046)\end{array}$ \\
\hline \multicolumn{7}{|c|}{ First moments } \\
\hline$c_{t} / y_{t}$ & $\begin{array}{c}0.760 \\
(0.023)\end{array}$ & $\begin{array}{c}0.743 \\
(0.033)\end{array}$ & $\begin{array}{c}0.751 \\
(0.024)\end{array}$ & $\begin{array}{c}0.750 \\
(0.020)\end{array}$ & $\begin{array}{c}0.749 \\
(0.019)\end{array}$ & $\begin{array}{c}0.752 \\
(0.024)\end{array}$ \\
\hline$k_{t} / y_{t}$ & $\begin{array}{c}9.958 \\
(0.526)\end{array}$ & $\begin{array}{l}11.030 \\
(0.872)\end{array}$ & $\begin{array}{l}10.358 \\
(0.595)\end{array}$ & $\begin{array}{l}10.382 \\
(0.570)\end{array}$ & $\begin{array}{l}10.346 \\
(0.521)\end{array}$ & $\begin{array}{l}10.382 \\
(0.643)\end{array}$ \\
\hline$n_{t}$ & $\begin{array}{c}0.212 \\
(0.008)\end{array}$ & $\begin{array}{c}0.208 \\
(0.011)\end{array}$ & $\begin{array}{c}0.213 \\
(0.009)\end{array}$ & $\begin{array}{c}0.211 \\
(0.007)\end{array}$ & $\begin{array}{c}0.213 \\
(0.008)\end{array}$ & $\begin{array}{c}0.212 \\
(0.008)\end{array}$ \\
\hline \multicolumn{7}{|c|}{ Second moments } \\
\hline$\sigma_{c}$ & $\begin{array}{c}0.631 \\
(0.078)\end{array}$ & $\begin{array}{l}0.548 \\
0.079\end{array}$ & $\begin{array}{c}0.592 \\
(0.084)\end{array}$ & $\begin{array}{c}0.675 \\
(0.078)\end{array}$ & $\begin{array}{c}0.648 \\
(0.075)\end{array}$ & $\begin{array}{c}0.638 \\
(0.080)\end{array}$ \\
\hline$\sigma_{y / n}$ & $\begin{array}{c}0.663 \\
(0.069)\end{array}$ & $\begin{array}{c}0.862 \\
(0.092)\end{array}$ & $\begin{array}{c}0.698 \\
(0.072)\end{array}$ & $\begin{array}{c}0.770 \\
(0.073)\end{array}$ & $\begin{array}{c}0.759 \\
(0.080)\end{array}$ & $\begin{array}{c}0.751 \\
(0.080)\end{array}$ \\
\hline$\sigma_{n}$ & $\begin{array}{c}1.272 \\
(0.142)\end{array}$ & $\begin{array}{c}1.301 \\
(0.430)\end{array}$ & $\begin{array}{c}1.311 \\
(0.192)\end{array}$ & $\begin{array}{c}1.066 \\
(0.132)\end{array}$ & $\begin{array}{c}1.068 \\
(0.121)\end{array}$ & $\begin{array}{c}1.200 \\
(0.128)\end{array}$ \\
\hline$\sigma_{i}$ & $\begin{array}{c}4.136 \\
(0.487)\end{array}$ & $\begin{array}{c}4.494 \\
(5.271)\end{array}$ & $\begin{array}{c}4.165 \\
(1.525)\end{array}$ & $\begin{array}{c}3.103 \\
(0.435)\end{array}$ & $\begin{array}{c}2.881 \\
(0.352)\end{array}$ & $\begin{array}{c}3.534 \\
(0.401)\end{array}$ \\
\hline$\sigma_{y}$ & $\begin{array}{c}1.406 \\
((0.161)\end{array}$ & $\begin{array}{c}1.122 \\
(0.400)\end{array}$ & $\begin{array}{c}1.359 \\
(0.172)\end{array}$ & $\begin{array}{l}1.144 \\
(0153)\end{array}$ & $\begin{array}{c}1.128 \\
(0.134)\end{array}$ & $\begin{array}{c}1.256 \\
(0.148)\end{array}$ \\
\hline $\operatorname{corr}(c, y)$ & $\begin{array}{c}0.921 \\
(0.019)\end{array}$ & $\begin{array}{c}0.717 \\
(0.081)\end{array}$ & $\begin{array}{c}0.890 \\
(0.042)\end{array}$ & $\begin{array}{c}0.841 \\
(0.047)\end{array}$ & $\begin{array}{c}0.901 \\
(0.030)\end{array}$ & $\begin{array}{c}0.850 \\
(0.043)\end{array}$ \\
\hline $\operatorname{corr}(y / n, y)$ & $\begin{array}{c}0.421 \\
(0.136)\end{array}$ & $\begin{array}{c}0.170 \\
(0.141)\end{array}$ & $\begin{array}{c}0.320 \\
(0.156)\end{array}$ & $\begin{array}{c}0.431 \\
(0.122)\end{array}$ & $\begin{array}{c}0.408 \\
(0.129)\end{array}$ & $\begin{array}{c}0.369 \\
(0.124)\end{array}$ \\
\hline $\operatorname{corr}(n, y)$ & $\begin{array}{c}0.880 \\
(0.035)\end{array}$ & $\begin{array}{c}0.739 \\
(0.082)\end{array}$ & $\begin{array}{c}0.858 \\
(0.048)\end{array}$ & $\begin{array}{c}0.754 \\
(0.066)\end{array}$ & $\begin{array}{c}0.757 \\
(0.069)\end{array}$ & $\begin{array}{c}0.810 \\
(0.053)\end{array}$ \\
\hline $\operatorname{corr}(i, y)$ & $\begin{array}{c}0.975 \\
(0.006)\end{array}$ & $\begin{array}{c}0.885 \\
(0.189)\end{array}$ & $\begin{array}{c}0.964 \\
(0.039)\end{array}$ & $\begin{array}{c}0.929 \\
(0.022)\end{array}$ & $\begin{array}{c}0.951 \\
(0.015)\end{array}$ & $\begin{array}{c}0.938 \\
(0.019)\end{array}$ \\
\hline $\operatorname{corr}(y / n, n)$ & $\begin{array}{l}-0.051 \\
(0.158)\end{array}$ & $\begin{array}{l}-0.524 \\
(0.117)\end{array}$ & $\begin{array}{l}-0.197 \\
(0.148)\end{array}$ & $\begin{array}{l}-0.255 \\
(0.143)\end{array}$ & $\begin{array}{c}-0.274 \\
(0.141)\end{array}$ & $\begin{array}{l}-0.236 \\
(0.142)\end{array}$ \\
\hline
\end{tabular}


the first column of the table. The statistics $\sigma_{x}$ and $\operatorname{corr}(x, z)$ are the volatility of a variable $x$ and the correlation between variables $x$ and $z$, respectively. The model's moments are sample averages of the statistics computed for each of 400 simulations. Each simulated series has a length of 157 periods, as do time series for the U.S. economy. The numbers in brackets are sample standard deviations of the statistics. Before calculating the second moments, we logged the corresponding variables for the U.S. and artificial economies and detrended them by using the Hodrick-Prescott filter with a penalty parameter equal to $1600 .^{10}$

\section{Results}

In this section, we present the simulation results. We begin by considering the case in which the economy only experiences shocks to technology.

- Model 1: $\rho_{\theta \theta}$ is estimated under the restriction $\rho_{X \theta}, \rho_{\theta X}, \rho_{X X} \equiv 0$.

This version of the model has been extensively studied in the literature, e.g., Hansen (1985), and Christiano and Eichenbaum (1992). These two papers use different values for the coefficient of autocorrelation $\rho_{\theta \theta}$ : The first one assumes $A R(1)$ with $\rho_{\theta \theta}=0.95$, while the second one uses the randomwalk specification, $\rho_{\theta \theta}=1$. As can be seen in Table 1 , our own estimate is close to the latter one. ${ }^{11}$

A comparison between the results of Hansen (1985) and those of Christiano and Eichenbaum (1992) shows that the key properties of the model are not substantially affected by a variation in the coefficient of autocorrelation.

essentially the result of differing definitions of the model's variables. In particular, we define the variable "output" as a sum of consumption and investment in the data, while the above two papers define output as GDP.

${ }^{10}$ To check the robustness of our results to a filtering procedure, we recompute all of the statistics, both in the model and in the data, under Baxter and King's (1999) band-pass filter with frequency components of between 6 and 32 quarters, and with 12 lags, which is the parameterization that corresponds to the quarterly data. We find that the results under the two filters used are practically identical.

${ }^{11}$ We find that the estimate of the autocorrelation coefficient $\rho_{\theta \theta}$ depends significantly on which particular time series is used as a proxy for working hours. If we use aggregate working hours, as Hansen (1985) does, the estimates for $\rho_{\theta \theta}$ will be about 0.95 . However, if we use the definition proposed by Christiano and Eichebaum (1992), which is adopted in this paper, the estimate for $\rho_{\theta \theta}$ will be close to one. 
Specifically, in either case, the model can generate most of the statistics in line with the data, except for those with respect to labor markets. The most serious failure of the model is its inability to account for the Dunlop-Tarshis observation, which was that productivity (wage) and hours worked in real economies are weakly correlated. In fact, the quantitative expression of the Dunlop-Tarshis observation varies substantially, depending on the time series used. For example, Christiano and Eichenbaum (1992) calculate the correlation between productivity and hours worked for the U.S. economy by computing the aggregate hours worked from two different household data sets and obtain values of -0.2 and 0.16. According to Gomme and Greenwood (1995), if the real wages are used as a proxy for productivity, this statistic is -0.44 .

As it turns out, the model does not even come close to any of the above numbers, but consistently predicts that the correlation between productivity and working hours is close to one. In addition, it considerably over-states the correlation between productivity and hours worked, and understates the volatility of productivity and the volatility of working hours when compared to the data.

We next turn to the case in which all uncertainty in the economy comes from shocks to preferences.

- Model 2: $\rho_{X X}$ is estimated under the restriction $\rho_{X \theta}, \rho_{\theta X}, \rho_{\theta \theta} \equiv 0$.

This version of the model proves to be highly unsuccessful in reproducing the data. It generates several serious failures, such as very low volatility in consumption, output and investments, and an almost perfect negative correlation between productivity (output) and working hours. It is interesting to note that, in this case, the problem is exactly the opposite to the one that we had before: the productivity (output) and working hours in the model are too countercyclical in comparison to the U.S. data.

We now consider the model with shocks to both technology and preferences.

- Model 3: $\rho_{\theta \theta}, \rho_{X \theta}, \rho_{\theta X}, \rho_{\theta \theta}$ are estimated without restrictions.

Once both types of shocks are assumed, the model's predictions improve considerably compared to those of Models 1 and 2. To be more specific, Model 3 generates a weakly negative correlation between productivity and 
hours worked and, therefore, accounts for the Dunlop-Tarshis observation. Furthermore, the correlation between productivity and output in the model is close to that in the data. Finally, the inclusion of the two different types of shocks increases the volatility of all the model's variables (except that of investment), which improves the model's fit to the data. In particular, the volatility of working hours in Model 3 is more than twice as large as in Model 1 and comes close to its empirical counterpart.

Bencivenga (1992) was first one to study a variant of Kydland and Prescott's (1982) model with both preference and technology shocks. She assumes a logarithmic utility function that is additive in consumption and leisure, and postulates two different kinds of preference shocks, one to the consumption term and the other to the leisure term of the utility function. ${ }^{\circ}$ (She argues that such preference shocks can result from fluctuations in household production or changes in relative prices.) Furthermore, she assumes a Cobb-Douglas production function and a full depreciation of capital, in which case the model admits a closed-form solution. ${ }^{12}$ Bencivenga (1992) finds that if the model is calibrated to match the aggregate time-series data, it predicts a weakly negative correlation between working hours and productivity. However, the model considered in Bencivenga (1992) has several important shortcomings: it dramatically over-predicts the volatilities of such model's variables, like consumption (by a factor of six), output (by a factor of three), labor (by a factor of four) and labor productivity (by a factor of two), and it predicts a wrong (negative) sign of the correlations between consumption and productivity and between output and productivity.

Maliar and Maliar (2003a) study the quantitative implications of the aggregation-based model (1), (2) by parameterizing the technology and preference shocks to reproduce evidence from U.S. household data, specifically, the distribution of wealth (equivalently, the distribution of welfare weights) and the process for the idiosyncratic labor productivity shocks. This paper assumes that the process for idiosyncratic shocks is given by the sum of the aggregate and individual components. It turns out that, under this assumption, the volatility of the aggregate component, measured from the data, is relatively less than that of the individual component, so that the idiosyncratic shocks are practically uncorrelated across agents. The aggregation of such idiosyncratic shocks leads to considerably small preference shocks,

\footnotetext{
${ }^{12}$ Bencivenga's (1992) model can be obtained from (1), (2) by setting $d=1, \gamma=1$, $\sigma=1, g=1$ and by adding a multiplicative shock to the consumption term in (1).
} 
so that the role played by preference shocks in aggregate dynamics is quite modest.

A comparison between the predictions of our Model 3 and those of Bencivenga's (1992) model shows that the excessive volatility in the latter model is derived, first, from the assumption of full depreciation of capital, which makes capital and therefore, other variables too volatile, and secondly, from the assumption of consumption preference shocks, which, in particular, explains why consumption is more volatile than output is. Regarding a comparison of the implications between our Model 3 and those of Maliar and Maliar's (2003a) setup, we conclude that the insignificant impact of the preference shocks on the aggregate economy's behavior in the latter paper is the result of the calibration procedure used, which does not seem to fully capture the co-movement of idiosyncratic shocks of different agents. However, the correlation between the idiosyncratic shocks across agents is likely to be reflected in the aggregate time-series data, which we have used for calibration in the present paper. This is what explains the differing results.

To complete our analysis, we shall investigate how robust our results are to modifications in the model's key parameters. We start from the sensitivity analysis with respect to the autocorrelation coefficients by considering the following experiment.

- Model 4: $\rho_{\theta \theta} \equiv 0.95, \rho_{X X} \equiv 0.95$ and $\rho_{X \theta}, \rho_{\theta X} \equiv 0$.

As it follows from the table, this modification not only preserves the positive features of the previous setup but also allows us to bring the model's predictions about the volatilities of investment, output and working hours closer to the data. We have done some other experiments (not reported), and found that the model's implications are very robust to changes in the autocorrelation coefficients.

We next explore how the model's predictions are affected by changes in the values of the preference parameters $(\gamma, \sigma, \delta)$. Below, we report the results of experiments in which we vary the value of one of the parameters $(\gamma, \sigma, \delta)$, while holding the remaining two parameters equal to the baseline values. In all of these experiments, the autocorrelation coefficients are estimated from the data with no additional restrictions. Models 5-10 are as follows:

- Models 5, 6: $\sigma=1.0, \delta=1.03^{-0.25}$ and $\gamma \in\{0.75,1.5\}$.

- Models 7, 8: $\gamma=1.0, \delta=1.03^{-0.25}$ and $\sigma \in\{0.5,2.0\}$. 
- Models 9, 10: $\gamma=1.0, \sigma=1.0$ and $\delta \in\left\{1.05^{-0.25}, 1.015^{-0.25}\right\}$.

The results of this simulation exercise are reported in Table 2. First of all, we should explain that the fact that the estimated coefficients of the autocorrelation $\rho_{\theta \theta}$ in Models 6 and 8 are greater than one does not imply non-stationarity. For the process for shocks $\theta_{t}$ and $X_{t}$ to be stationary, it is sufficient that both eigenvalues of the matrix constructed from the autocorrelation coefficients lie within the unit root circle, see, e.g., Hamilton (1994). This restriction is satisfied in each of the cases considered.

As we can see from Table 2, the variations considered in the preference parameters $(\gamma, \sigma, \delta)$ do not significantly affect the properties of the model. An exception is Model 6 , in which the correlation between productivity and working hours becomes too negative. Even this value however is not entirely inconsistent with the data, because it is reasonably close to the correlation between real wages and working hours in the U.S. economy. In summary, we conclude that the model's predictions are robust to changes in the key parameter values.

\section{Conclusion}

This paper investigates the quantitative implications of a one-consumer neoclassical growth model with two types of shocks, one to technology and another to preferences. The model studied is derived from aggregation: it describes the aggregate behavior of a heterogeneous-agent economy, in which agents face perfectly insurable idiosyncratic shocks to earnings. The possibility of aggregation enables us to infer the properties of aggregate dynamics of the underlying heterogeneous-agent economy by imposing restrictions exclusively at the aggregate level, as is typically done in the RBC literature; the distributive dynamics need not be characterized explicitly.

The main finding of this paper is that if the aggregation-based model with both technology and preference shocks is calibrated to match the U.S. time-series data, it explains the key features of business cycle fluctuations in the U.S. economy surprisingly well. Moreover, to account for the data, we do not need shocks to both the consumption and leisure terms of the utility function, as assumed in Bencivenga (1992). It is sufficient just to have a shock to the leisure term of the utility function that is obtained on the grounds of the aggregation theory in Maliar and Maliar (2003a). 


\section{References}

[1] Atkeson, A. , and M. Ogaki (1996) 'Wealth-varying intertemporal elasticities of substitution: evidence from panel and aggregate data,' Journal of Monetary Economics 38, 507-535

[2] Baxter, M., and R. King (1999) 'Measuring business cycles: approximate band-pass filters for economic time series,' Review of Economics and Statistics 81, 575-593

[3] Caselli, F., and J. Ventura (2000) 'A representative consumer theory of distribution,' American Economic Review 90, 909-26

[4] Chatterjee, S. (1994) 'Transitional dynamics and the distribution of wealth in a neoclassical growth model,' Journal of Public Economics $54,97-119$

[5] Christiano, L., and M. Eichenbaum (1992) 'Current real-business-cycle theories and aggregate labor-market fluctuations,' American Economic Review 82, 430-450

[6] den Haan, W., and A. Marcet (1990) 'Solving the stochastic growth model by parameterizing expectations,' Journal of Business and Economic Statistics 8, 31-34

[7] Dunlop J. (1938) 'The movements of real and money wage rates,' Economic Journal 48, 413-434

[8] Gomme, P., and J. Greenwood (1995) 'On the cyclical allocation of risk,' Journal of Economic Dynamics and Control 19, 91-124

[9] Hamilton, J. (1994) Time series analysis (Princeton: Princeton University Press) 291-351

[10] Hansen, G. (1985) 'Indivisible labor and the business cycle,' Journal of Monetary Economics 16, 309-328

[11] Hansen, L. (1982) 'Large sample properties of generalized method of moments estimators,' Econometrica 50, 1029-54 
[12] King, R., C. Plosser, and S. Rebelo (1988) 'Production, growth, and business cycles I: the basic neoclassical model,' Journal of Monetary Economics 21, 195-232

[13] King, R., and S. Rebelo (1999) 'Resucitating real business cylces,' in Handbook of Macroeconomics, ed. J. Taylor and M. Woodford (Netherland: Elsevier)

[14] Kydland, F., and E. Prescott (1982) 'Time to build and aggregate fluctuations,' Econometrica 50, 1345-1370

[15] Maliar, L., and S. Maliar (2001) 'Heterogeneity in capital and skills in a neoclassical stochastic growth model,' Journal of Economic Dynamics and Control 25, 1367-1397

[16] Maliar, L., and S. Maliar (2003a) 'The representative consumer in the neoclassical growth model with idiosyncratic shocks,' Review of Economic Dynamics 6, 362-380

[17] Maliar, L., and S. Maliar (2003b) 'Parameterized expectations algorithm and the moving bounds,' Journal of Business and Economic Statistics $21,88-92$

[18] Tarshis, L. (1939) 'Changes in real and money wages,' Economic Journal 49, 150-154

\section{Appendix}

In this appendix, we describe the conditions used for the estimation of the model's parameters with the GMM procedure. The economy's budget constraint (2) implies that the gross investment $i_{t}$ is related to the capital stock $k_{t}$ by

$$
E\left\{1-d+\left(i_{t+1} / k_{t}\right)-\left(k_{t+1} / k_{t}\right)\right\}=0 .
$$

The assumption of the balanced growth yields

$$
\begin{aligned}
& E\left\{\ln \left(y_{t}\right)-\ln \left(y_{t-1}\right)-\ln (g)\right\}=0, \\
& E\left\{\ln \left(c_{t}\right)-\ln \left(c_{t-1}\right)-\ln (g)\right\}=0,
\end{aligned}
$$




$$
E\left\{\ln \left(k_{t}\right)-\ln \left(k_{t-1}\right)-\ln (g)\right\}=0 .
$$

The intertemporal first-order condition of the problem $(1),(2)$ is

$$
E\left\{1-\delta\left(c_{t} / c_{t+1}\right)\left[1-d+\alpha\left(y_{t} / k_{t}\right)\right]\right\}=0 .
$$

The intratemporal first-order condition of (1),(2), expressed in the logarithms, is

$\ln \left(X_{t}\right)=-\gamma\left[\ln \left(c_{t}\right)-g t\right]+\sigma \ln \left(1-h_{t}\right)+\ln \left[(1-\alpha) y_{t} / h_{t}\right]-\ln (g) t-\ln (A)$.

Finally, with the assumption of the Cobb-Douglas production function, we have

$$
\ln \left(\theta_{t}\right)=\ln \left(y_{t}\right)-\alpha \ln \left(k_{t}\right)-(1-\alpha) \ln \left(h_{t}\right)-(1-\alpha) \ln (g) t-\ln (\theta),
$$

where $\theta$ denotes the absolute level of technology. 